\title{
Present and future association between obesity and hypogonadism in Italian male
}

\author{
Valentina Boddi $^{1}$, Valeria Barbaro ${ }^{2}$, Paul Mc Nieven ${ }^{3}$, Mario Maggi ${ }^{1}$, Carlo Maria Rotella ${ }^{2}$ \\ ${ }^{1}$ Sexual Medicine and Andrology Unit, Department of Clinical Physiopathology University of Florence, Florence, Italy; \\ ${ }^{2}$ Department of Biochemical Experimental and Clinical Science, Section of Endocrinology and Obesity Agency, \\ Careggi University Hospital; \\ 3 Strategyst Consulting Inc.
}

\begin{abstract}
Summary Objective: Obesity prevalence is increasing worldwide and it is nowadays considered a real public health problem. Obesity is associated with co-morbidities like cardiovascular diseases (CVD) and type 2 diabetes mellitus (T2DM), furthermore visceral obesity can be related to low testosterone $(T)$ plasma levels. The link between obesity and hypogonadism (HG) is complex and not completely clarified. Current guidelines suggest that screening for HG should be done in subjects with obesity and T2DM. The aim of this evaluation is to assess the estimated actual and future prevalence of obesity and related co-morbidities, in particular $H G$, in the Italian general population.

Materials and Methods: The Strategyst Consulting Inc. recently completed an epidemiology forecast model for several countries, looking at HG and CV/Metabolic Disease, based on National Health and Nutrition Examination Survey (NHANES) data collected between 1999-2010. Data from NHANES survey were used to evaluate the Italian estimated prevalence of obesity and HG. Results: Results show that obesity estimated prevalence will increase in 2030 also in Italy. In addition, also the prevalence of obese CVD and T2DM subjects will increase too. Even Italian HG prevalence is estimated to increase in the next two decades, irrespective of $T$ threshold considered $(<8,10$ and $12 \mathrm{nmol} / \mathrm{L})$. In obese CVD subjects the relative risk (RR) of developing $H G(T<8$ $n m o l / L)$ is four times greater than in not-CVD obese subjects $(R R=4.1,3.1$ and 1.9 accordingly to the aforementioned $T$ thresholds for defining HG). Accordingly, the estimated percentage of hypogonadal obese CVD and T2DM subjects will rise in 2030.

Conclusions: The Strategyst epidemiology forecast model has allowed to assess the current and future prevalence of obesity and its relative co-morbidities like HG in Italy. Data emerged from this evaluation suggest that obesity and $H G$ prevalence will increase in Italian population and confirm the complex link between adipose tissue and male $T$ levels.
\end{abstract}

KEY WORDS: Visceral obesity; Hypogonadism; Future prevalence; Epidemiological forecast model.

Submitted 19 December 2013; Accepted 28 February 2014

\section{INTRODUCTION}

Obesity is an excessive accumulation of body fat mass relative to lean body mass, usually due to unbalanced diet and sedentary lifestyle (1). According to the World Health Organization (WHO) the diagnosis of obesity is often based on body mass index (BMI), calculated as weight in kilograms divided by height in meters squared $\left(\mathrm{kg} / \mathrm{m}^{2}\right)$. Individuals with BMI higher than $30 \mathrm{~kg} / \mathrm{m}^{2}$ are considered obese. Obesity is categorized in grade 1 , if $\mathrm{BMI}$ is of 30 to less than 35; grade 2, if BMI of 35 to less than 40 and grade 3 , if BMI is of $40 \mathrm{~kg} / \mathrm{m}^{2}$ or greater (2). Obesity is the greatest public health problem in the world: several studies reported an association between obesity and increasing risk of developing CVD, cancer and common chronic disease, such as T2DM and hypertension, all diseases that can lead to a reduced quality of life and premature death (3). Moreover, visceral obesity has been associated with alteration in sex steroid hormone concentrations like HG, especially in adult males (4-7). The Organization for Economic Co-operation and Development (OECD) projections suggest that more than 2 in 3 people will be overweight or obese in some of the OECD countries by 2020 (http://www.oecd.org/els/healthsystems/obesityandtheeconomicsofpreventionfitnotfat.htm). Indeed, we are facing with a real global epidemic that is spreading in many countries and it can cause, in the absence of immediate action, very serious health problems in the coming years (1). The Strategyst Consulting Inc. recently completed an epidemiology forecast model for several countries, looking at HG and CV/Metabolic Disease, based on NHANES data collected between 1999-2010. Data from NHANES were used to show the degree of overlap between disease states and then to modify the raw prevalence values in NHANES in order to match the local prevalence in the particular countries, such as Italy. The aim of this evaluation is to assess the current and future prevalence of obesity and its relative comorbidities, mostly HG, in Italy.

\section{MATERIAL AND METHOdS}

NHANES is a cross-sectional study designed to assess the health and nutritional status of adults and children in the 
United States. In this survey every subject underwent an interview and an extensive physical examination. In some cases a morning blood sample was collected for biochemical and hormonal analyses, such as $\mathrm{T}$ in male (9). Informations on age and race/ethnicity were self-reported. During physical examination, height and weight, as well as waist and hip circumferences were measured and BMI was calculated as weight in kilograms divided by the square of height in meters. Participants were defined as having diabetes if they answered "yes" to the question, "Have you ever been told by a doctor or other health professional you had diabetes or sugar diabetes?" and as having CVD if they answered yes to the question, "Have you ever been told by a doctor you had heart attack, an angina pectoris or a coronary heart disease?" (9). Detailed information regarding the collection of data in NHANES is available elsewhere (NHANES III data files, documentation, and codebooks. Available online from http://www.cdc.gov/nchs/ nhanes/about_nhanes.htm).

The Strategyst Consulting Inc recently completed an epidemiology forecast model for several countries, looking at Hypogonadism and Cardiovascular/Metabolic Disease, based on National Health and Nutrition Examination Survey (NHANES) data collected between 1999-2010. Data from NHANES were analyzed for understanding the general CV/metabolic patient population, as well as the distribution of $\mathrm{T}$ levels within the pool, knowing that this differs by age and BMI, and possibly also by CV status. From this data the percentages of relative risk of developing CVD and T2DM were calculated in the U.S. population and then applied for other countries, includ- ing Italy, on the basis of WHO data. WHO had previously performed several forecasting evaluation on $\mathrm{CV}$ and metabolic health across the world.

This allowed Strategyst Consulting Inc. to make projections for each country of the $\mathrm{CV}$ and metabolic diseases from 2013 to 2030. T levels are pretty consistent across the globe, with variations between countries being due to varying demographic profiles and levels of obesity and CV risk factors. For this reason, only NHANES testosterone data were used, as they were the only source that allowed to create HG populations with respect to all the risk factors (and their mutual comorbidities), and embody the very complex set of Odds Ratios that describe these populations. Hence, data from NHANES were used to show the degree of overlap between disease states, then to modify the raw prevalence values in NHANES to match the local prevalence in the particular country analyzed.

\section{RESULTS AND DISCUSSION}

\section{Prevalence and trends of obesity in Italian adults}

In the last thirty years, the worldwide prevalence of obesity has almost doubled, not with homogeneously distribution (11). United States is one of the countries that experienced the largest absolute increase in the number of overweight and obese people between 1980 and 2008 (11). About 35\% of U.S adults were obese in 2011-2012, with a higher percentage of middle-aged obese adults aged 40-59 than younger adults aged 20-39 or older adults aged 60

\section{Panel B-C.}

Percentage of obesity as a function of age bands in Italy, actually (Panel B) and in 2030 (Panel C).

Figure 1.

Panel A.

Male obesity prevalence from 2013 to 2030 in Italy.

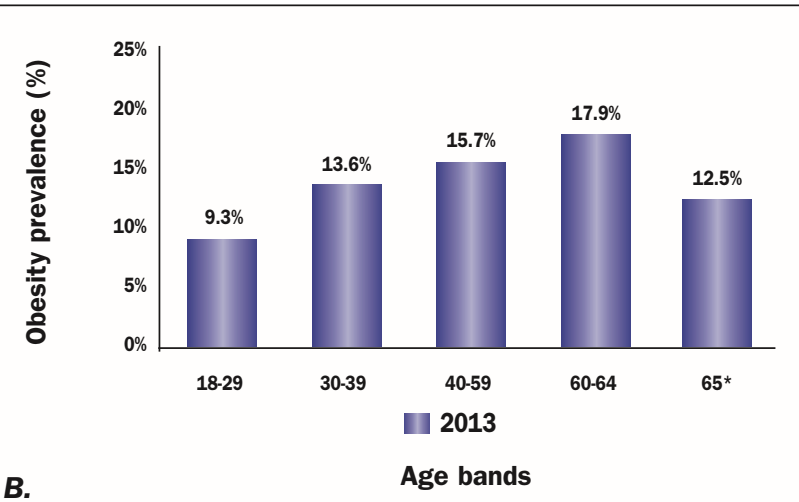

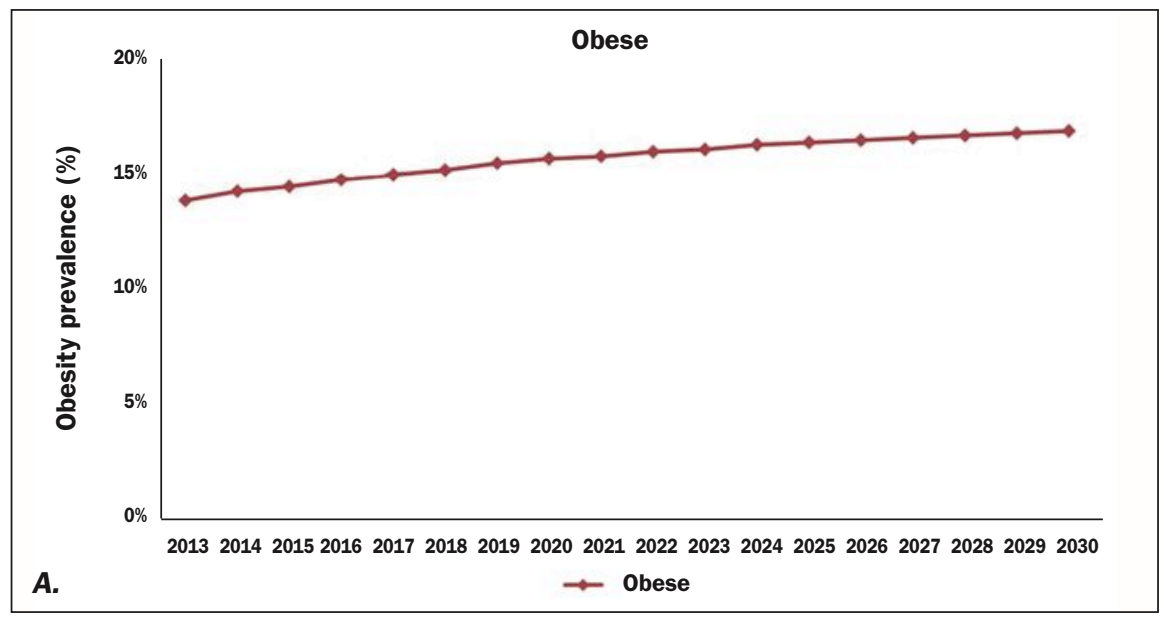


and over (12). According to data released in 2008 by the OECD, in Italy about 1 person in 10 was obese (http://www.oecd.org/els/health-systems/obesityandtheeconomicsofpreventionfitnotfat-italykeyfacts.htm).

Figure 1 shows the trend of obesity (BMI $\geq 30 \mathrm{~kg} / \mathrm{m}^{2}$ ) prevalence in Italy from 2013 to 2030, in the adult male population (18-over 65 years old). At present, according to Strategyst estimated data, 13.8\% of Italian men is obese. This prevalence is similar to that referred by PASSI (Progressi delle Aziende Sanitarie per la Salute in Italia), a monitoring system of Italian population (http://www.epicentro.iss.it/problemi/obesita/epid.asp). Obesity prevalence will increase in the coming years and, on the basis of our estimated data, it will reach $16.8 \%$ in 2030 (Figure 1, Panel A).

Nowadays, among Italian adult obese subjects, there is a higher percentage of patients aged 60-64 (17.9\%) than aged $40-59(15.7 \%)$ or aged 65 and over (12.5\%) (Figure 1 , Panel B). In the next future, the percentage of obesity is estimated to rise in each age group, but mostly in middle aged adults, reaching $22.6 \%$ among $40-59$ years old men and $21.7 \%$ among $60-64$ years old men, similarly to US male population (Figure 1, Panel C).
Prevalence and trends of CVD and T2DM in Italian adults The INTERHEART study group identified the abdominal (visceral) obesity as one of the nine major risk factors for myocardial infarction (including smoking, lipids, hypertension, T2DM, diet, physical activity, alcohol consumption, and psychosocial factors), accounting for more than $90 \%$ of the worldwide risk (15). These risk factors were shared by men and women, almost in every geographic region and every racial/ethnic group. It is well known that visceral obesity, versus subcutaneous fat, is characterized by a hypersecretion of pro-atherogenic, pro-inflammatory and pro-diabetic adipo-cytokines, and by an enhanced free fatty acid turnover and toxicity (16), an increased basal sympathetic tone, a hypercoagulable state and a chronic low-grade systemic inflammation (17). This causes the development of insulin resistance (IR) and the increased risk of CVD as ischemic heart diseases (angina and myocardial infarction, MI) and congestive heart failure (CHF). In addition, visceral obesity can be considered a "conditional" risk for developing T2DM, dyslipidaemia and hypertension, all independent CV risk factors (17). Figure 2, Panel A shows that the prevalence of T2DM, angina, history of MI and CHF is expected to grow highly in the coming
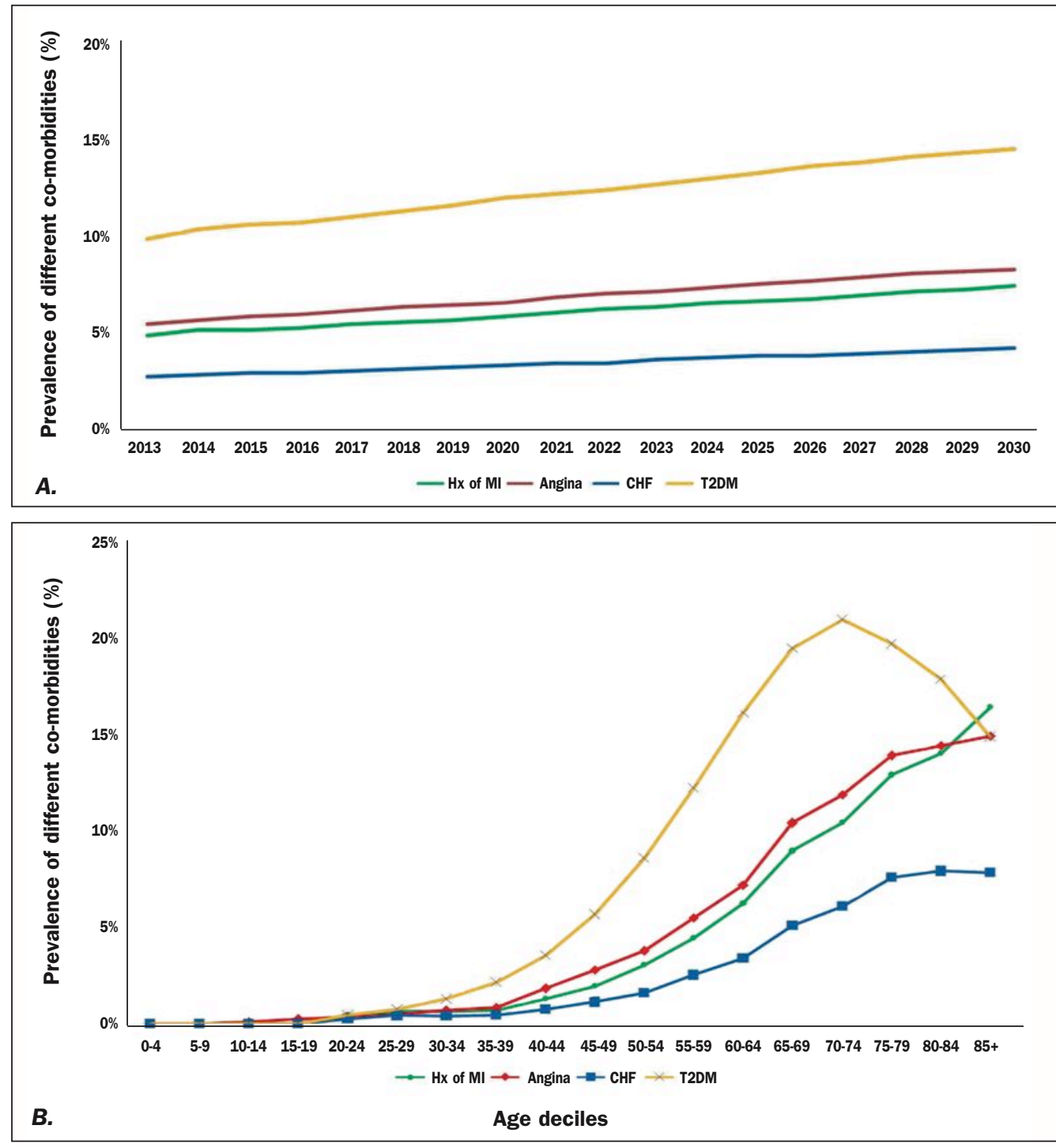

Figure 2.

\section{Panel A.}

Male prevalence of different co-morbidities from 2013 to 2030 in Italy [History of Myocardial Infarction (MI), Angina, Congestive Heart Failure (CHF) and type 2 Diabetes Mellitus (T2DM)].

Panel B.

Male prevalence of different co-morbidities as a function of different age bands in Italy (History of MI, Angina, $\mathrm{CHF}$ and T2DM). 

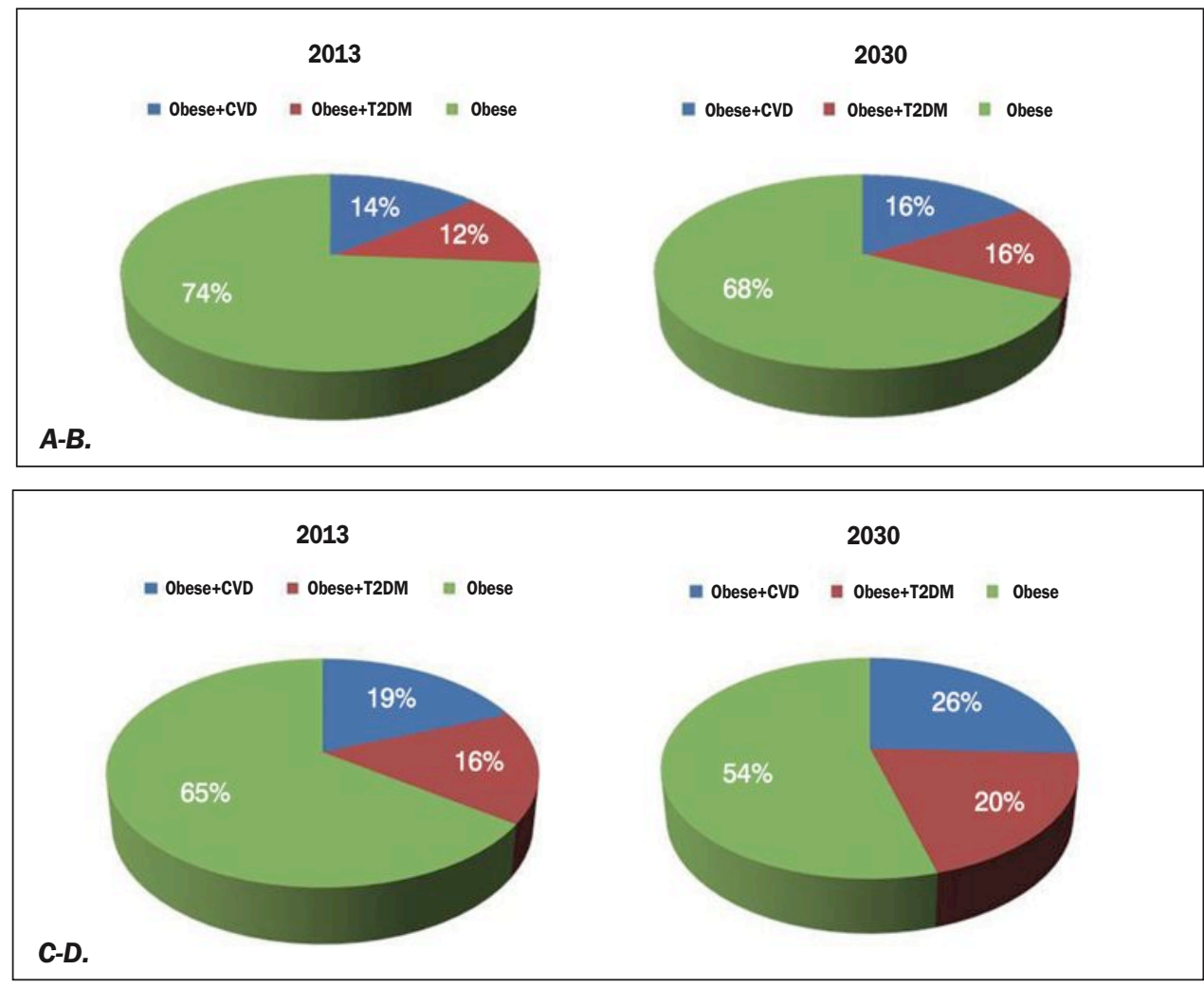

Figure 3.

Panel A-B.

Estimated distribution of obese male sample in 2013 and 2030; Panel $A$ and Panel B, respectively.

\section{Panel C-D.}

Estimated distribution of hypogonadal obese male sample in 2013 and 2030; Panel $C$ and Panel D, respectively. years. At the moment, the estimated Italian proportion of men with a history of $\mathrm{MI}$ is $4.8 \%$, of angina $5.4 \%$, of $\mathrm{CHF}$ $2.7 \%$ and of T2DM $9.8 \%$ reaching $7.4 \%, 8.2 \%, 4.2 \%$ and $14.4 \%$, respectively, in 2030 . Hence, the prevalence of CV and metabolic diseases will be almost doubled within 17 years in Italy. Concerning the prevalence of angina, history of MI, CHF and T2DM as a function of age, it rapidly increases for all these diseases with aging, especially after 40 years old. In particular, for T2DM reaches a prevalence of 21\% in 70 years old men (Figure 2, Panel B). In 2013, among the estimated obese sample, $26 \%$ has co-morbidities like T2DM and CVD (12\% and 14\%, respectively), whereas 74\% has not (Figure 3, Panel A). Normal weight subjects have lower rates of CVD (13\%) and T2DM (10\%), respectively (data not shown).

This is consistent with a higher prevalence of $\mathrm{CV}$ and metabolic diseases in obese subjects. It is estimated that the prevalence of "unhealthy" obese (with CVD and T2DM) will rise reaching 32\% in 2030 (16\% T2DM and $16 \%$ CVD) whereas "healthy" obese (without CV and metabolic morbidity) will decrease to $68 \%$ (Figure 3, Panel B). Overall these data show that prevalence of obesity in Italy will increase, in particular the percentage of obese male subjects with co-morbidities.

Prevalence and trends of hypogonadism in Italian adults Normal aging is characterized by a slight decline of $\mathrm{T}$ levels (18). Considering changes in $\mathrm{T}$ levels by age, there is not a consensus for definition of HG (19). For example, the American Association of Clinical Endocrinologists (20) and the Endocrine Society (21) proposed different T cutoffs for diagnosing HG, i.e. $7 \mathrm{nmol} / \mathrm{L}$ (200 ng/dl) and $10.4 \mathrm{nmol} / \mathrm{L}(300 \mathrm{ng} / \mathrm{dl})$ respectively.
According to a consensus among different scientific Andrology Societies $(18,19,22)$ men with T levels below $8 \mathrm{nmol} / \mathrm{L}$ (231 ng/dl) should receive $\mathrm{T}$ replacement therapy, whereas those with $\mathrm{T}$ levels above $12 \mathrm{nmol} / \mathrm{L}$ (346 $\mathrm{ng} / \mathrm{dl}$ ) should not be treated. Moreover, it was introduced the concept of the so-called "late-onset hypogonadism" (LOH): a clinical and biochemical condition of the advancing age, characterized by peculiar symptoms and by low levels of serum T, i.e. total T below $12 \mathrm{nmol} / \mathrm{L}$. (2123). Recently, Wu et al. (24) proposed a T cut off 11 $\mathrm{nmol} / \mathrm{L}(230 \mathrm{ng} / \mathrm{dl})$ and free $\mathrm{T}$ levels of less than 220 $\mathrm{pmol} / \mathrm{L}(<64 \mathrm{pg} / \mathrm{ml})$ for diagnosing $\mathrm{LOH}$, in the presence of at least three sexual symptoms (low libido and reduced spontaneous and sex-related erections).

Therefore, the estimated number of hypogonadal men is different, depending on the $\mathrm{T}$ cut off used and on age (18). In Italy, by Strategyst model evaluation, the present estimated prevalence of $\mathrm{HG}$ is $7,12.5$ and $22 \%$ considering $\mathrm{T}<8,10$ e $12 \mathrm{nmol} / \mathrm{L}$, respectively. It is expected that, in 2030, this prevalence will rise reaching 8.1, 14.7 and $24.2 \%$, respectively (Figure 4, Panel A).

In observational studies involving male general population, the prevalence of $H G$ is increasing as a function of age, although at a different rate, as observed in US (2527) and European male population (24). Accordingly, analyzing Strategyst Italian forecast, HG prevalence increases by age irrespective of $\mathrm{T}$ threshold considered, with the highest rate in older subjects ( $>65$ years old) reaching $7,12.5,22 \%$, for $\mathrm{T}$ levels $<8,10,12 \mathrm{nmol} / \mathrm{L}$, respectively (Figure 4 , Panel B).

\section{Obesity and hypogonadism}

Several studies have demonstrated an inverse relationship 


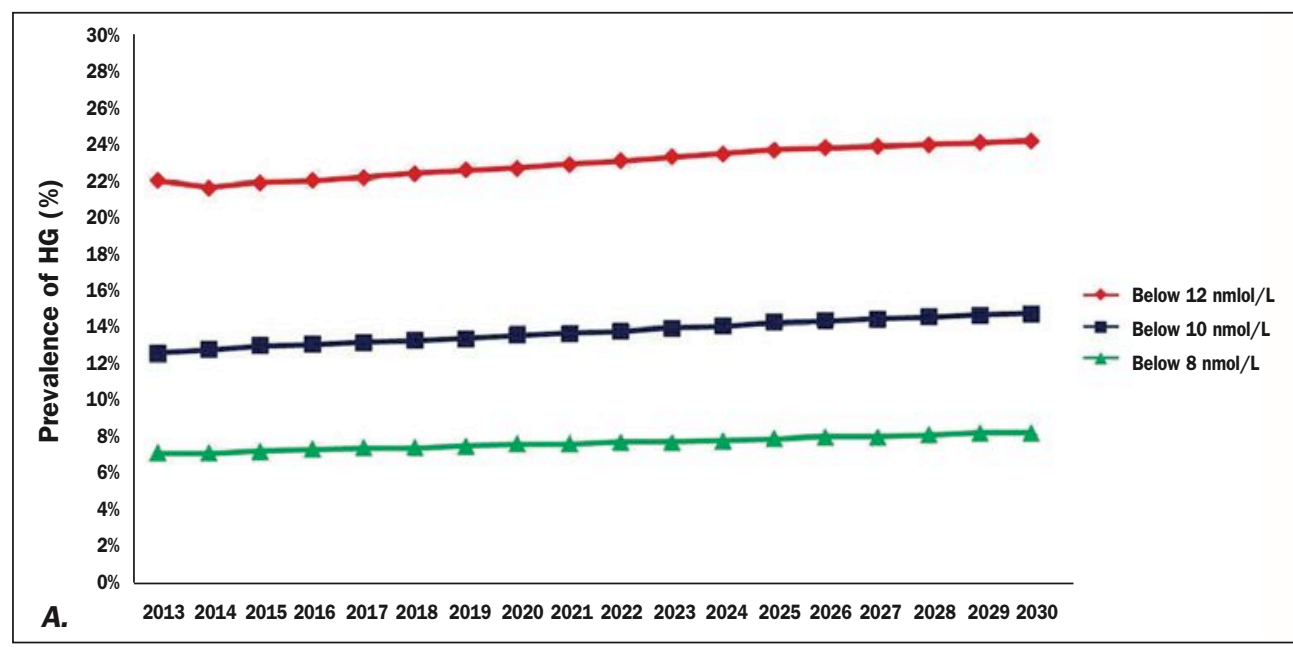

Figure 4.

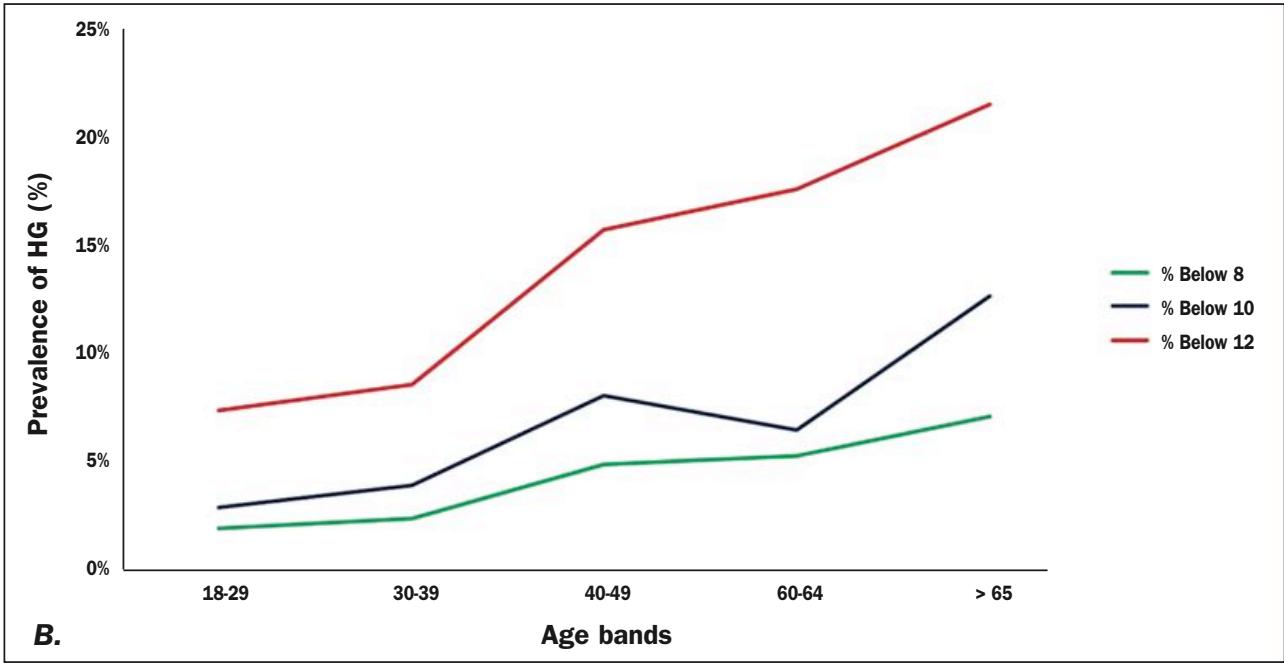

Panel A.

Estimated Italian hyponadism $(\mathrm{HG})$ prevalence from 2013 to 2030 , considering different testosterone $(T)$ cut off.

Panel B.

Prevalence of hyponadism (HG) as a function of age bands, considering different testosterone cut off, in Italy.

between BMI and waist circumference, indicators of visceral obesity, and T levels over all age groups (28-30). An increase in BMI from normal weight to obese range may be equivalent to a 15 years fall in T levels (23). In the Massachusetts Male Aging Study (MMAS) authors demonstrated that a healthy lifestyle, a normal body weight and the absence of chronic disease were more important determinants of androgen levels than ageing (25-26). The link between obesity and HG is complex and not completely understood. Visceral obesity can probably be considered an important cause of HG, but at the same time, HG could be a cause of obesity and insulin resistance, consequently establishing a vicious cycle (31-35).

Figure 5, Panel A shows that the estimated percentage of obese males in Italy is higher in HG sample than in general population. There are some considerable evidences on the role of $\mathrm{T}$ in regulating body composition. It seems that $\mathrm{T}$ concurs in increasing and maintaining muscle mass and reducing fat mass (36).

This suggests a possible role of T deficiency in the etiology of obesity so that HG might be considered an additional component of Metabolic Syndrome (MetS) in males (37). In fact, in men undergoing androgen ablation therapy for advanced prostate cancer it was observed a significant increase in total body fat mass and reduction in lean body mass (38).
Criteria for MetS were present in more than $50 \%$ of these men, predisposing them to higher CV risk (39). The relationship between reduced T levels and CVD still represents a matter of speculation. Cross-sectional epidemiological studies clearly show a significant association between HG and CVD (40-41). In a recent meta-analysis Araujo et al. demonstrated that HG was associated with an increased risk of all causes and CVD mortality (42).

Figure 5, Panel B shows the estimated Italian prevalence of HG (as different T threshold considered: 8, 10, $12 \mathrm{nmol} / \mathrm{L}$ ) in obese subjects with or without previous CVD. In obese CVD subjects the relative risk (RR) of developing HG $(\mathrm{T}<8 \mathrm{nmol} / \mathrm{L})$ is four times greater than in not-CVD obese subjects $(\mathrm{RR}=4.1,3.1$ and 1.9 accordingly to $\mathrm{T}$ cut off of $8,10$ e $12 \mathrm{nmol} / \mathrm{L})$.

This is a cross-sectional analyses, therefore we cannot establish a relationship of causality, however this suggests that the presence of previous CVD predispose obese subjects to develop $\mathrm{HG}$ and this risk is higher for lower $\mathrm{T}$ plasma levels. A large body of evidence supports the association between low T, T2DM and MetS (31-35). According to data shown in Figure 5B, in Italy the estimated percentage of hypogonadal obese male subjects with T2DM and CVD is 19 and $16 \%$, respectively (Figure 3, Panel C), higher than in subjects with only obesity (Figure 3, Panel A). 


\section{Figure 5.}

Panel A. Percentage of obese and nonobese Italian men in hypogonadal sample (HG sample) and general population.

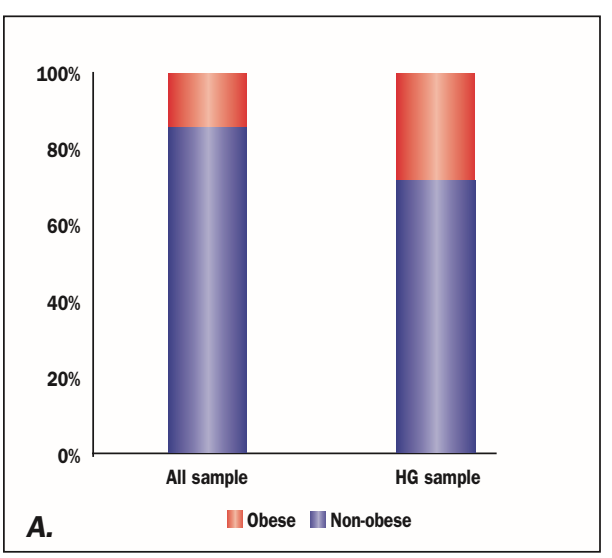

Panel B. Hypogonadism (HG) prevalence in obese and cardiovascular disease (CVD) and obese subjects in Italy according to different testosterone thresholds.

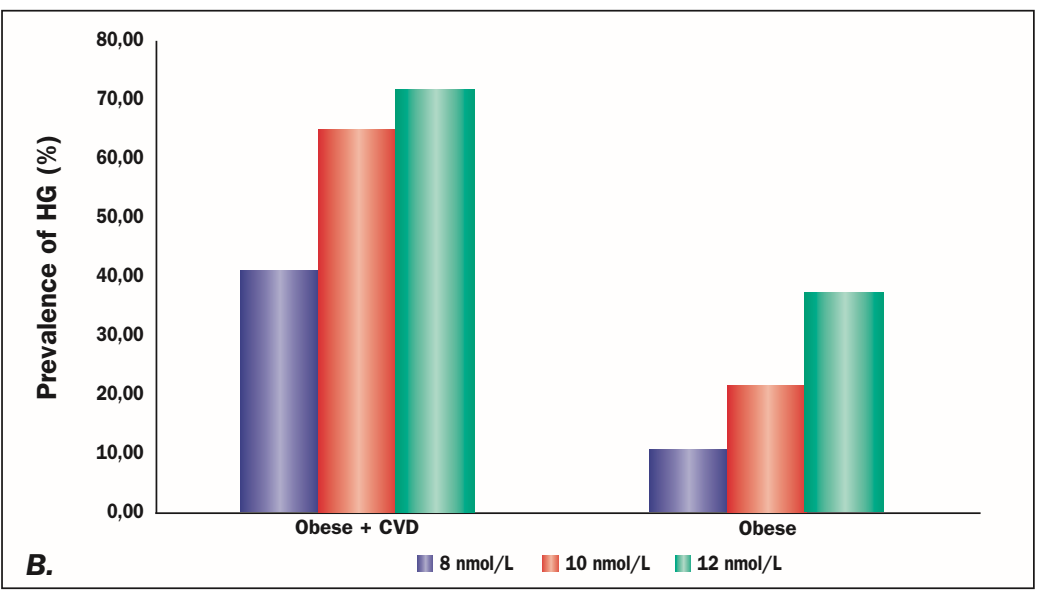

Hence, the presence of HG confers a higher probability of developing CVD and T2DM. Furthermore, the estimated percentage of obese hypogonadal subjects with CVD and T2DM will rise in 2030, reaching 26 and 20\% respectively (Figure 3, Panel D).

This is consistent with previously shown data. Current guidelines suggest that screening for HG should be done in subjects with obesity, T2DM and MetS (18, 19, 21).

\section{Conclusion}

Obesity prevalence is increasing worldwide and this phenomenon involves Italy too. At this moment, 13.8\% men are obese and they will became $16.8 \%$ in 2030. The increase of prevalence will be greater in middle aged adult male. In coming years also the prevalence of T2DM, angina, CHF and history of MI will rise. Italian obese subjects have a higher rate of T2DM and CVD and this rate is estimated to rise.

Obesity is also related to HG. The estimated prevalence of HG in Italy differs according to different cut offs proposed by Scientific Society, from 2 to $22 \%$ and will increase until 8-24\% in 2030. Concerning the data shown in this evaluation, the estimated prevalence of HG increases as a function of age and hypogonadal subjects are more often obese than general population.

Conversely, obese subjects have a higher risk of developing HG, in particular if they have suffered from CVD. Finally, obese-hypogonadal males have a higher rate of T2DM and CVD than eugonadal obese male.

The Strategyst epidemiology forecast model allowed to assess the current and future prevalence of obesity and its relative comorbidities like HG in Italy. A limitation of the present report should be recognized: prevalence estimations for Italy are based on epidemiological values of US male population which could be different from the Italian one.

However, data emerged from this evaluation suggests that obesity and $H G$ prevalence will increase in the Italian population and confirm the complex link between adipose tissue and male $\mathrm{T}$ levels.

\section{REFERENCES}

1. Caterson ID, Gill TP. Obesity epidemiology and possible prevention. Best Pract Res Clin Endocrinol. 2002; 16:595-610.

2. World Health Organization Physical status: the use and interpretation of anthropometry. Technical report series 1995, no. 854. In: Geneva: WHO, 1995.

3. Prospective Studies Collaboration. Body-mass index and causespecific mortality in 900000 adults: collaborative analyses of 57 prospective studies. Lancet. 2009; 373:1083-1096.

4. Haffner SM, Valdez RA, Stern MP, Katz MS. Obesity, body fat distribution and sex hormones in men. Int J Obes Relat Metab Disord. 1993; 17:643-9.

5. Corona G, Rastrelli G, Forti G \& Maggi M. Update in testosterone therapy for men. J Sex Med. 2011; 8:639-654.

6. Corona G, Rastrelli G, Vignozzi L \& Maggi M. Emerging medication for the treatment of male hypogonadism. Expert Opin Emerg Drugs. 2012; 17:239-59.

7. Corona G, Rastrelli G, Vignozzi L, Mannucci E \& Maggi M. How to recognize late-onset hypogonadism in men with sexual dysfunction. Asian J Androl. 2012; 14:251-259.

8. http://www.oecd.org/els/health-systems/49716427.pdf

9. Selvin E, Feinleib M, Zhang L, et al. Androgens and diabetes in men: results from the Third National Health and Nutrition Examination Survey (NHANES III). Diabetes Care. 2007; 30:234-8.

10. http://www.cdc.gov/nchs/nhanes/about_nhanes.htm

11. Pérez Rodrigo C. Current mapping of obesity. Nutr Hosp. 2013; 28 (Suppl 5):21-31.

12. Cynthia L Ogden, Margaret D Carroll, Brian K Kit, et al. Prevalence of Obesity Among Adults: United States, 2011-2012 NCHS Data Brief No. 131 October 2013.

13. http://www.oecd.org/els/health-systems/obesityandtheeconomicsofpreventionfitnotfat-italykeyfacts.htm

\section{4. http://www.epicentro.iss.it/problemi/obesita/epid.asp.}

15. Yusuf S, Hawken S, Ounpuu S, et al. INTERHEART Study Investigators. Effect of potentially modifiable risk factors associated with myocardial infarction in 52 countries (the INTERHEART study): case-control study. Lancet. 2004; 364:937-52. 
16. Hajer GR, van Haeften TW, Visseren FL. Adipose tissue dysfunction in obesity, diabetes, and vascular diseases. Eur Heart J. 2008; 29:2959-71.

17. Krauss RM, Winston M, Fletcher BJ, Grundy SM. Obesity: impact on cardiovascular disease. Circulation. 1998; 98:1472-76.

18. Buvat J, Maggi M, Guay A, Torres LO. Testosterone deficiency in men: systematic review and standard operating procedures for diagnosis and treatment. J Sex Med. 2013; 10:245-84.

19. Wang $C$, Nieschlag $E$, Swerdloff $R$, et al. Investigation, treatment and monitoring of late-onset hypogonadism in males: ISA, ISSAM, EAU, EAA and ASA recommendations. Eur J Endocrinol. 2008; 159:507-514.

20. Petak SM, Nankin HR, Spark RF, et al. American Association of Clinical Endocrinologists Medical Guidelines for clinical practice for the evaluation and treatment of hypogonadism in adult male patients--2002 update. Endocr Pract. 2002; 8:440-56

21. Bhasin S, Cunningham GR, Hayes FJ, et al. Task Force, Endocrine Society. Testosterone therapy in men with androgen deficiency syndromes: an Endocrine Society clinical practice guideline. J Clin Endocrinol Metab. 2010; 95:2536-2559.

22. Nieschlag E, Swerdloff R, Behre HM, et al. Investigation, treatment and monitoring of late-onset hypogonadism in males: ISA, ISSAM, and EAU recommendations. Int J Androl. 2005; 28:125-7.

23. Wu FC, Tajar A, Pye SR, et al. Hypothalamic-pituitary-testicular axis disruptions in older men are differentially linked to age and modifiable risk factors: the European Male Aging Study. J Clin Endocrinol Metabol. 2008; 93:2737-2745.

24. Wu FC, Tajar A, Beynon JM, et al. EMAS Group. Identification of late-onset hypogonadism in middle-aged and elderly men. N Engl J Med. 2010; 363:123-35.

25. Mohr BA, Guay AT, O'Donnell AB, McKinlay JB. Normal, bound and nonbound testosterone levels in normally ageing men results from the Massachusetts Male Ageing Study. Clin Endocrinol (Oxf). 2005; 62:64-73

26. Yeap BB, Almeida OP, Hyde Z, et al. 2008. Healthier lifestyle predicts higher circulating testosterone in older men. The Health in Men Study. Clin. Endocrinol. (Oxf.) 2009; 70:455-63.

27. Rohrmann S, Platz EA, Selvin E, et al. The prevalence of low sex steroid hormone concentrations in men in the Third National Health and Nutrition Examination Survey (NHANES III). Clin Endocrinol. (Oxf). 2011; 75:232-9.

28. Traish AM, Feeley RJ, and Guay A. Mechanisms of obesity and related pathologies: androgen deficiency and endothelial dysfunction may be the link between obesity and erectile dysfunction. Febs J 2009; 276:5755-67.

29. Traish AM, Saad F, Guay A. The dark side of testosterone deficiency: II. Type 2 diabetes and insulin resistance. J Androl. 2009; 30:23-32.

30. Corona G, Mannucci E, Ricca V, et al. The age-related decline of testosterone is associated with different specific symptoms and signs in patients with sexual dysfunction. Int J Androl. 2009; 32:720-8.

31. Corona G, Rastrelli G, Morelli A, et al. Hypogonadism and metabolic syndrome. J Endocrinol Invest. 2011; 34:557-567.

32. Corona G, Monami M, Rastrelli G, et al. Type 2 diabetes mellitus and testosterone: a meta-analysis study. Int J Androl. 2011; 34:528-540

33. Corona G, Monami M, Rastrelli $G$, et al. Testosterone and metabolic syndrome: a meta-analysis study. J Sex Med. 2011; 8:272-283.
34. Corona G, Mannucci E, Forti G, Maggi M. Following the common association between testosterone deficiency and diabetes mellitus, can testosterone be regarded as a new therapy for diabetes? Int J Androl. 2009; 32:431-441.

35. Saad F, Aversa A, Isidori AM, et al. Onset of effects of testosterone treatment and time span until maximum effects are achieved. Eur J Endocrinol. 2011; 165:675-685.

36. Emmelot-Vonk MH, Verhaar HJ, Nakhai Pour HR, et al. Effect of testosterone supplementation on functional mobility, cognition, and other parameters in older men: a randomized controlled trial. JAMA. 2008; 299:39-52.

37. Corona G, Mannucci E, Forti G, Maggi M. Hypogonadism, ED, metabolic syndrome and obesity: a pathological link supporting cardiovascular diseases. Int J Androl. 2009; 32:587-98.

38. Chen Z, Maricic M, Nguyen P, et al. Low bone density and high percentage of body fat among men who were treated with androgen deprivation therapy for prostate carcinoma. Cancer. 2002; 95:2136-2144.

39. Braga-Basaria M, Dobs AS, Muller DC, et al. Metabolic syndrome in men with prostate cancer undergoing long-term androgendeprivation therapy. J Clin Oncol. 2006; 24:3979-3983.

40. Ruige JB, Mahmoud AM, De Bacquer D, Kaufman JM. Endogenous testosterone and cardiovascular disease in healthy men: a metaanalysis. Heart. 2011; 97:870-5.

41. Corona $G$, Monami M, Boddi V, et al. Low testosterone is associated with an increased risk of MACE lethality in subjects with erectile dysfunction. J Sex Med. 2010; 7:1557-64.

42. Araujo AB, Dixon JM, Suarez EA, et al. Clinical review: Endogenous testosterone and mortality in men: a systematic review and meta-analysis. J Clin Endocrinol Metab. 2011; 96:3007-19.

\section{Correspondence}

Valentina Boddi, MD vboddi@gmail.com

Mario Maggi, MD m.maggi@dfc.unifi.it

Sexual Medicine and Andrology Unit, Department of Clinical Physiopathology University of Florence

Viale Pieraccini 6 - 50139 Florence, Italy

Paul Mc Nieven, MD

pm@strategyst-consulting.com

Strategyst Consulting Inc.

Carlo Maria Rotella, MD (Corresponding Author)

c.rotella@dfc.unifi.it

Valeria Barbaro, MD

valeb2282@gmail.com

Department of Biochemical Experimental and Clinical Science Section of Endocrinology and Obesity Agency

Careggi University Hospital, Florence, Italy 